\title{
Modulation of TNF- $\alpha$-induced endothelial cell activation by glucosamine, a naturally occurring amino monosaccharide
}

\author{
YINGHUA JU ${ }^{1,4}$, JIAN HUA ${ }^{1}$, KOJI SAKAMOTO ${ }^{3}$, HIDEOKI OGAWA ${ }^{2}$ and ISAO NAGAOKA ${ }^{1}$ \\ ${ }^{1}$ Department of Host Defense and Biochemical Research, ${ }^{2}$ Atopy (Allergy) Research Center, \\ Juntendo University, School of Medicine, Hongo, Bunkyo-ku, Tokyo 113-8421; ${ }^{3}$ Koyo Chemical Co., Ltd., \\ Iidabashi, Chiyoda-ku, Tokyo 102-0072, Japan; ${ }^{4}$ Department of Biochemistry and Molecular Biology, \\ College of Basic Medical Sciences, China Medical University, Shenyang 110001, P.R. China
}

Received August 14, 2008; Accepted October 2, 2008

DOI: 10.3892/ijmm_00000089

\begin{abstract}
Atherosclerosis is now considered a chronic inflammatory disease, and glucosamine has the potential to exhibit an anti-inflammatory action. Thus, we investigated the effect of glucosamine on tumor necrosis factor $\alpha$ (TNF- $\alpha)$ induced endothelial cell activation. Human umbilical vein endothelial cells (HUVECs) were stimulated by TNF- $\alpha$ in the presence or absence of glucosamine or its analogue, N-acetylglucosamine. mRNA expression of MCP-1 (a chemoattractant protein) and ICAM-1 (an adhesion molecule) was evaluated by real-time RT-PCR, and their protein levels were analyzed by ELISA and Western blotting, respectively. Furthermore, the effects of glucosamine on the phosphorylation of p38MAPK and $\mathrm{NF}-\kappa \mathrm{B}$, and $O-\mathrm{N}$-acetylglucosamine $(O-\mathrm{GlcNAc})$ modification were evaluated by Western blotting. The results demonstrated that glucosamine but not $\mathrm{N}$-acetylglucosamine suppressed TNF- $\alpha$-induced expression of MCP-1 and ICAM-1 at both the mRNA and protein levels. Furthermore, glucosamine abrogated the phosphorylation of p38MAPK and $\mathrm{NF}-\kappa \mathrm{B}$. To note, glucosamine induced $O$-GlcNAc modification, which was negatively correlated with the expression of MCP-1 and ICAM-1, and phosphorylation of p38MAPK and $\mathrm{NF}-\kappa \mathrm{B}$. Thus, glucosamine is likely to suppress endothelial cell activation (TNF- $\alpha$-induced ICAM- 1 and MCP-1 expression) possibly by affecting p38MAPK and NF- $\mathrm{BB}$ signaling via $O$-GlcNAc modification.
\end{abstract}

\section{Introduction}

In recent years, the findings of various clinical and pathological studies have altered the theories concerning the pathogenesis

Correspondence to: Dr Isao Nagaoka, Department of Host Defense and Biochemical Research, Juntendo University, School of Medicine, 2-1-1 Hongo, Bunkyo-ku, Tokyo 113-8421, Japan

E-mail: nagaokai@juntendo.ac.jp

Key words: glucosamine, $O$-N-acetylglucosamine modification, intercellular adhesion molecule-1, monocyte chemoattractant protein-1, endothelial cell of atherosclerosis. Although large lipid deposits can be observed in atheromatous lesions and the role of different lipoproteins are thought to be involved in its pathogenesis, atherosclerosis is no longer considered to be a primary disorder of lipid accumulation (1). It is a state of disordered immunity in which there is dynamic interaction between endothelial dysfunction, inflammation and repeated cycles of 'wound healing response' (2). Expression of endothelial cell adhesion molecules such as intercellular adhesion molecule (ICAM-1), induces the binding of monocytes and lymphocytes, thus initiating an inflammatory process that ultimately leads to the formation of atherosclerotic plaque (3). The migration of inflammatory cells to the subendothelial space is facilitated by chemoattractants such as monocyte chemoattractant protein-1 (MCP-1) and oxidized low-density lipoprotein $(4,5)$. Once migrated to the subendothelial space, monocytes mature into macrophages and express scavenger receptors to internalize modified lipoproteins, which gives rise to lipid-laden macrophages or foam cells (6). Proinflammatory cytokines, such as tumor necrosis factor- $\alpha$ $(\mathrm{TNF}-\alpha)$ and interleukin-1ß (IL-1 $\beta$ ), are found in atherosclerotic lesions, and have been known to contribute to the inflammatory process (7). Previous studies have shown that these cytokines can induce the expression of cell adhesion molecules, chemokines and genes in endothelial cells involved in the regulation of vessel tonicity, thrombosis and recruitment of leukocytes (8).

Glucosamine, a naturally occurring amino monosaccharide, acts as a preferred substrate for the biosynthesis of glycosaminoglycan and has been used for the treatment of osteoarthritis more than two decades (9). Several short- and long-term clinical trials of osteoarthritis have shown the significant symptom-modifying effect of glucosamine with no side effects (10). Furthermore, glucosamine has been shown to inhibit the expression of inducible nitric oxide synthase in macrophages (11), and neutrophil functions such as superoxide generation, phagocytosis, granule enzyme release, chemotaxis and CD11b expression (12), thereby possibly exhibiting an anti-inflammatory action. More recently, glucosamine has been shown to inhibit ICAM-1 expression in human retinal pigment epithelial cells, which suggests a potential of glucosamine to attenuate inflammation in eyes (13). Based on these 
findings, we hypothesized that glucosamine may affect the endothelial cell activation. In this study, we investigated the effect of glucosamine on the activation of endothelial cells (expression of a monocyte chemoattractant factor MCP-1 and an adhesion molecule ICAM-1) induced by TNF- $\alpha$, a cytokine expressed in atherosclerotic lesions, as a sequel to our previous research (14).

\section{Materials and methods}

Reagents. D-Glucosamine hydrochloride was supplied from Koyo Chemical Co. (Tokyo, Japan). N-Acetyl-D-glucosamine was purchased from Wako Pure Chemical Industries, Ltd. (Osaka, Japan); alloxan monohydrate from Sigma Chemical Co. (St. Louis, MO); TNF- $\alpha$ from Pepro Tech. EC Ltd. (London, UK); SB203580, a p38MAPK inhibitor and BMS-345541, an IKK (IкB kinase) inhibitor, which downregulates NF- $\kappa$ B activation, from Calbiochem (Darmstadt, Germany).

Endothelial cells. Human umbilical vein endothelial cells (HUVECs) and endothelial cell medium EGM-2 were purchased from Sanko Junyaku Co. (Tokyo, Japan). HUVECs were maintained in EGM-2 medium at $37^{\circ} \mathrm{C}$ in a $\mathrm{CO}_{2}$ incubator. HUVECs were incubated in the presence or absence of 0.1-10 mM glucosamine, or 1 and $10 \mathrm{mM} \mathrm{N}$-acetylglucosamine for $2 \mathrm{~h}$, and then stimulated with $0.5 \mathrm{ng} / \mathrm{ml}$ TNF- $\alpha$ for $24 \mathrm{~h}$ at $37^{\circ} \mathrm{C}$, unless otherwise noted. In some experiments, HUVECs were preincubated with $0.5 \mathrm{mM}$ alloxan for $2 \mathrm{~h}$, and were further incubated with $0.1-10 \mathrm{mM}$ glucosamine for $2 \mathrm{~h}$ before stimulation with $0.5 \mathrm{ng} / \mathrm{ml}$ TNF- $\alpha$. Alternatively, HUVECs were preincubated with SB203580 (5-20 $\mu \mathrm{M})$ and BMS-345541 (1-4 $\mu \mathrm{M})$ for $2 \mathrm{~h}$ before TNF- $\alpha$ stimulation.

Analysis of MCP-1 and ICAM-1 mRNA expression by realtime RT-PCR. HUVECs were plated at $1.5 \times 10^{5} /$ well in 6 -well plates in EGM-2 medium for $24 \mathrm{~h}$ at $37^{\circ} \mathrm{C}(50-60 \%$ confluent). HUVECs were preincubated in the presence or absence of glucosamine or $\mathrm{N}$-acetylglucosamine, and then stimulated with TNF- $\alpha$. Thereafter, the total RNA was purified using an RNeasy Plus Mini Kit (Qiagen, Valencia, CA), and RT-PCR was performed using a ReverTra Dash RT-PCR Kit (Toyobo, Osaka, Japan). First-strand cDNA was synthesized with total RNA $(1 \mu \mathrm{g})$, a random primer and ReverTra Ace reverse transcriptase (Toyobo), and the RT reactions were carried out at $42^{\circ} \mathrm{C}$ for $20 \mathrm{~min}$, followed by termination at $99^{\circ} \mathrm{C}$ for $5 \mathrm{~min}$. Subsequently, a quantitative real-time PCR was performed using 7500 Real-Time PCR System (Applied Biosystems, Warrington, UK). Reactions were carried out in a reaction mixture consisting of $25 \mu 1$ solution containing power SYBR-Green PCR master mix (Applied Biosystems) and $200 \mathrm{nM}$ of each primer (ICAM-1, MCP-1 and GAPDH (glyceraldehyde 3-phosphate dehydrogenase) forward or reverse primer; Takara, Tokyo, Japan).

Analysis of MCP-1 expression by ELISA. HUVECs (50-60\% confluent in 24-well plates) were preincubated in the presence or absence of $0.1-1 \mathrm{mM}$ glucosamine or $1 \mathrm{mM} \mathrm{N}$ acetylglucosamine, and then stimulated with $0.5 \mathrm{ng} / \mathrm{ml} \mathrm{TNF}-\alpha$.
The supernatants were recovered and used for the quantification of MCP-1 using a Duoset MCP-1 ELISA Development System (R\&D System, UK).

Analysis of ICAM-1 expression by Western blotting. HUVECs (50-60\% confluent in 6-well plates) were preincubated in the presence or absence of 0.1-1 $\mathrm{mM}$ glucosamine or $1 \mathrm{mM}$ $\mathrm{N}$-acetylglucosamine, and then stimulated with $0.5 \mathrm{ng} / \mathrm{ml}$ TNF- $\alpha$. After washing with phosphate-buffered saline (PBS), the cells were harvested in $250 \mu 1$ of lysis buffer $(10 \mathrm{mM}$ Tris- $\mathrm{HCl}, \mathrm{pH} 7.4,1 \%$ Triton X-100, 100 mM NaCl, 0.5\% sodium deoxycholate, $1 \mathrm{mM}$ EDTA, $1 \mathrm{mM}$ EGTA and $1 \mathrm{mM}$ diisopropyl fluorophosphate) containing $1 / 25 \mathrm{v} / \mathrm{v}$ Complete $^{\mathrm{TM}}$ (Roche Molecular Biochemicals, Mannheim, Germany). Lysates were placed on ice for $30 \mathrm{~min}$ and centrifuged at $14,000 \mathrm{x} \mathrm{g}$ for $10 \mathrm{~min}$. The supernatants were recovered and mixed with sodium dodecyl sulfate (SDS)-polyacrylamide gel electrophoresis (PAGE) sample buffer and denatured at $100^{\circ} \mathrm{C}$ for $3 \mathrm{~min}$. Samples (10 $\mu \mathrm{g}$ protein/lane) were subjected to $10 \%$ SDS-PAGE, and separated proteins were transferred to polyvinylidene difluoride membranes (Millipore Corp., Bedford, MA). The membranes were blocked in 5\% skim milk and probed with rabbit anti-human ICAM-1 polyclonal antibody (H-108; Santa Cruz Biotechnology, Santa Cruz, CA). After washing with PBS-0.05\% Tween, membranes were further probed with horseradish peroxidase (HRP)-conjugated goat anti-rabbit IgG (Chemicon Intl., Temecula, CA), and the proteins were finally detected with SuperSignal West Pico chemiluminescent substrate (Pierce, Rockford, IL). The detected bands were quantified using LAS-3000 image analyzer and MultiGauge software (Fujifilm Corp., Tokyo, Japan).

Thereafter, the antibodies were stripped from the membranes using Restore Western Stripping Buffer (Pierce). GAPDH, a loading control, contained in each sample was detected with mouse anti-GAPDH monoclonal antibody (MAB374, Chemicon Intl.) and HRP-conjugated goat antimouse $\mathrm{IgG} / \mathrm{IgM}$ (Chemicon Intl.). The protein contents were determined with a BCA protein assay kit (Pierce).

Analysis of the phosphorylation of p38MAPK and $N F-\kappa B$. HUVECs (50-60\% confluent in 6-well plates) were incubated in the presence or absence of $0.1-10 \mathrm{mM}$ glucosamine or $1 \mathrm{mM} \mathrm{N}$-acetylglucosamine for $2 \mathrm{~h}$, and then stimulated with $0.5 \mathrm{ng} / \mathrm{ml} \mathrm{TNF}-\alpha$ for $10 \mathrm{~min}$ at $37^{\circ} \mathrm{C}$. After washing with PBS, the cells were harvested in $250 \mu 1$ of lysis buffer (1\% Triton $\mathrm{X}-100,0.5 \%$ Nonidet P-40, $10 \mathrm{mM}$ Tris- $\mathrm{HCl}, \mathrm{pH} 7.4,150 \mathrm{mM}$ $\mathrm{NaCl}, 1 \mathrm{mM}$ EDTA, $1 \mathrm{mM}$ EGTA, $2 \mathrm{mM} \mathrm{Na} \mathrm{VO}_{4}, 2 \mathrm{mM}$ $p$-nitrophenyl phosphate and $1 \mathrm{mM}$ diisopropyl fluorophosphate) containing 1/25 v/v Complete ${ }^{\mathrm{TM}}$ (Roche Diagnostic Systems, Mannheim, Germany). After sonication, the lysates were centrifuged at $14,000 \times \mathrm{g}$ for $5 \mathrm{~min}$. Samples $(10 \mu \mathrm{g}$ protein/lane) were subjected to $10 \%$ SDS-PAGE and blotted, as described in the detection of ICAM-1. Phosphorylated p38MAPK and NF- $\mathrm{BB}$ were detected by probing with mouse anti-phosphorylated p38MAPK monoclonal antibody (pT180/ pY182; BD Biosciences Pharmingen, San Diego, CA) and rabbit anti-phosphorylated NF-кB p65 antibody (Ser536; Cell Signaling Technology, Danvers, MA), and HRP-conjugated goat anti-mouse IgG/IgM and HRP-conjugated goat antirabbit $\mathrm{IgG}$, respectively. 
A

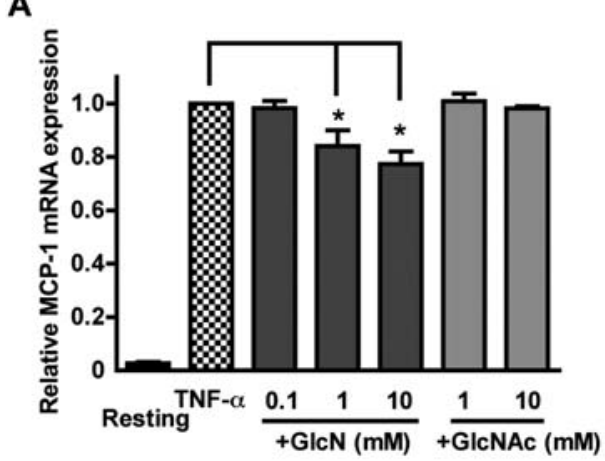

B

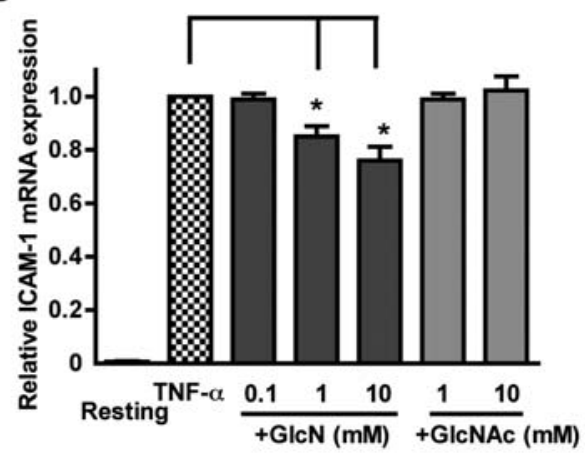

Figure 1. Effect of glucosamine on TNF- $\alpha$-induced MCP-1 and ICAM-1 mRNA expression in HUVECs. HUVECs were incubated without (Resting) or with $0.5 \mathrm{ng} / \mathrm{ml} \mathrm{TNF- \alpha}$ in the absence or presence of $0.1-10 \mathrm{mM}$ glucosamine $(\mathrm{GlcN})$, or 1 and $10 \mathrm{mM} \mathrm{N}$-acetylglucosamine (GlcNAc). MCP-1, ICAM-1 and GAPDH (loading control) mRNA was detected by real-time RT-PCR. MCP-1 (A) and ICAM-1 (B) mRNA expression was expressed as a ratio relative to $\mathrm{TNF}-\alpha$ stimulation alone. Data are the mean \pm SEM from 6 independent experiments; ${ }^{*} \mathrm{P}<0.05$.

After stripping, p38MAPK protein, a loading control contained in each sample, was detected by reprobing with mouse anti-p38MAPK (p38/SAPK2 $\alpha$; BD Biosciences Pharmingen) monoclonal antibody and HRP-conjugated goat anti-mouse $\mathrm{IgG} / \mathrm{IgM}$.

Detection of $\mathrm{O}-\mathrm{N}$-acetylglucosamine-modified proteins by Western blotting. HUVECs in 6-well plates were preincubated in the presence or absence of 0.1-1 $\mathrm{mM}$ glucosamine or $1 \mathrm{mM}$ $\mathrm{N}$-acetylglucosamine, and stimulated with $0.5 \mathrm{ng} / \mathrm{ml} \mathrm{TNF-} \alpha$. Alternatively, HUVECs were preincubated with alloxan for $2 \mathrm{~h}$ and further incubated with $1 \mathrm{mM}$ glucosamine for $2 \mathrm{~h}$ before TNF- $\alpha$ stimulation. Cells were lysed, and supernatant samples (15 $\mu \mathrm{g}$ protein/lane) were applied to 7.5\% SDSPAGE, and blotted membranes were immersed in $100 \%$ methanol and dried at room temperature. Membranes were next probed with mouse anti-O-GlcNAc ( $\mathrm{O}-\mathrm{O}$-linked Nacetylglucosamine) monoclonal antibody (CTD110.6; Covance, Berkeley, CA) in 1\% casein/PBS and further probed with HRP-conjugated goat anti-mouse $\operatorname{IgG/IgM}$ in $1 \%$ casein/PBS. The $O$-N-acetylglucosamine-modified proteins were detected and analyzed as described above.

Statistical analysis. Data were expressed as the mean \pm SEM, and analyzed for significant differences by a one-way analysis

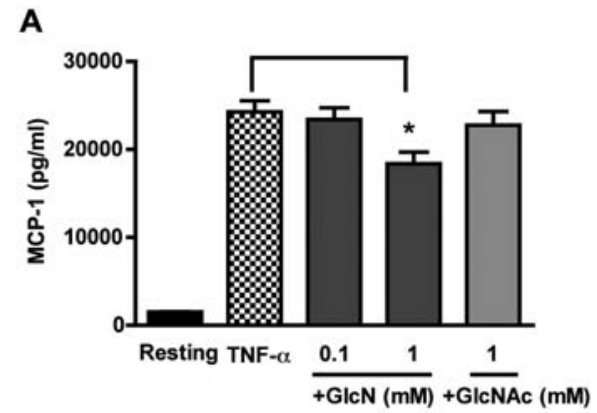

B
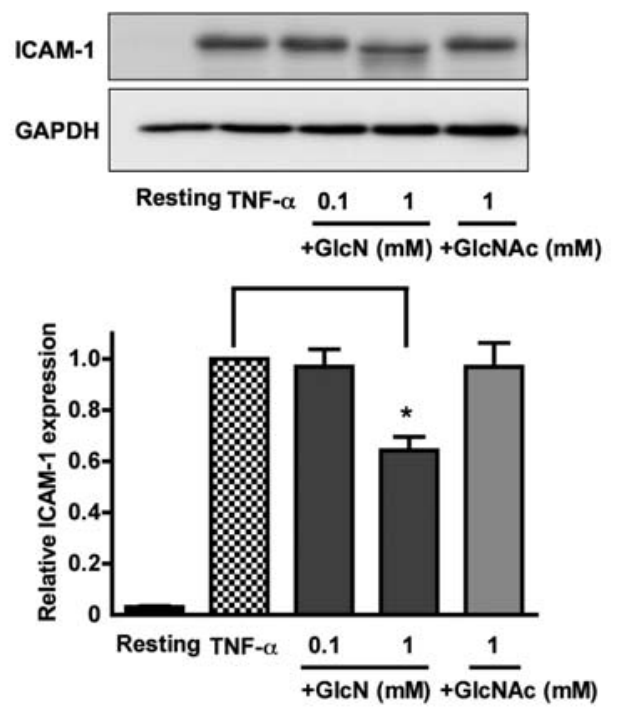

Figure 2. Effect of glucosamine on MCP-1 and ICAM-1 expression in HUVECs. HUVECs were incubated without (Resting) or with $0.5 \mathrm{ng} / \mathrm{ml}$ TNF- $\alpha$ in the absence or presence of $0.1-1 \mathrm{mM}$ glucosamine $(\mathrm{GlcN})$ or 1 $\mathrm{mM}$ N-acetylglucosamine (GlcNAc). Supernatants and cell lysates were recovered, and MCP-1 (A) and ICAM-1 (B) expression was quantitated by ELISA and Western blotting, respectively. GAPDH (a loading control) was also detected by Western blotting. The ICAM-1 level was expressed as a ratio relative to TNF- $\alpha$ stimulation alone. Data are the mean \pm SEM from 6 independent experiments; ${ }^{*} \mathrm{P}<0.05$.

of variance (ANOVA) with the multiple comparison test or the Student's t-test (Prism 4, GraphPad Software, San Diego, $\mathrm{CA})$. Differences were considered statistically significant at $\mathrm{P}<0.05$.

\section{Results}

Effect of glucosamine on TNF- $\alpha$-induced expression of MCP-1 and ICAM-1 mRNA. To evaluate the effect of glucosamine on the MCP-1 and ICAM-1 mRNA expression, we stimulated HUVECs with TNF- $\alpha$, a cytokine expressed in atherosclerotic lesions, in the absence or presence of glucosamine or N-acetylglucosamine. As shown in Fig. 1, glucosamine dosedependently inhibited the TNF- $\alpha$-induced expression of MCP-1 and ICAM-1 mRNA detected by real-time RT-PCR $(\mathrm{P}<0.05$ at 1 and $10 \mathrm{mM}$ glucosamine $)$. In contrast, $\mathrm{N}$-acetylglucosamine, an analogue of glucosamine, did not significantly affect the mRNA expression.

Effect of glucosamine on TNF- $\alpha$-induced expression of MCP-1 and ICAM-1 proteins. Because glucosamine inhibited MCP-1 
A

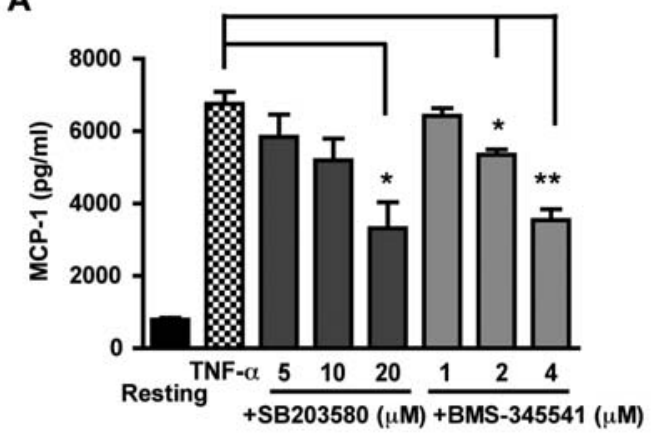

B

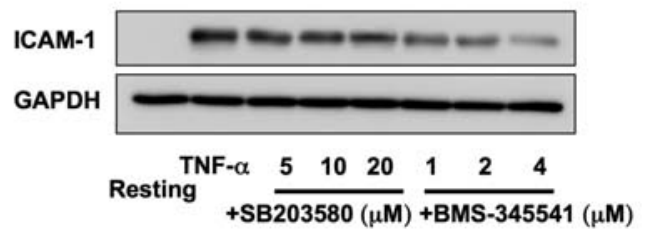

Figure 3. Effect of p38 MAPK and IKK inhibitors on TNF- $\alpha$-induced MCP-1 and ICAM-1 expression. HUVECs were incubated without (Resting) or with $0.5 \mathrm{ng} / \mathrm{ml} \mathrm{TNF}-\alpha$ in the absence or presence of $5-20 \mu \mathrm{M} \mathrm{SB} 203580$ (p38MAPK inhibitor) or 1-4 $\mu \mathrm{M}$ BMS-345541 (NF- $\mathrm{kB}$ inhibitor). Supernatants and cell lysates were recovered, and MCP-1 (A) and ICAM-1 (B) expression was quantitated by ELISA and Western blotting, respectively. GAPDH (a loading control) was also detected by Western blotting. Data are the mean \pm SEM for MCP-1 and one representatives for ICAM-1 from 6 independent experiments; ${ }^{*} \mathrm{P}<0.05,{ }^{* *} \mathrm{P}<0.01$

and ICAM-1 mRNA expression (Fig. 1), we then examined the effect of glucosamine on the TNF- $\alpha$-induced expression of MCP-1 and ICAM-1 proteins. Consistent with its suppressive effect on mRNA expression, glucosamine inhibited the protein expression of MCP-1 and ICAM-1 $(\mathrm{P}<0.05$ at $1 \mathrm{mM}$ glucosamine) (Fig. 2). As expected, N-acetylglucosamine did not affect the expression of these proteins. We confirmed that glucosamine further suppressed MCP-1 and ICAM-1 expression at $10 \mathrm{mM}$ (data not shown).

Effect of glucosamine on TNF- $\alpha$-induced phosphorylation of p38MAPK and $N F-\kappa B$. TNF- $\alpha$ activates a variety of signaling cascades (such as p38MAPK and NF-кB) which lead to the induction of inflammatory response, including adhesion molecule expression and proinflammatory cytokine production (15). Thus, we examined the involvement of p38MAPK and NF- $\mathrm{KB}$ in TNF- $\alpha$-induced MCP-1 and ICAM- 1 expression by using p38MAPK and IKK inhibitors. As shown in Fig. 3, both SB203580, a p38MAPK inhibitor, and BMS-345541, an IKK inhibitor, which down-regulates NF- $\mathrm{KB}$ activation, dose-dependently suppressed TNF- $\alpha$-induced MCP-1 and ICAM-1 expression; $20 \mu \mathrm{M}$ SB203580 and $4 \mu \mathrm{M}$ BMS inhibited the expression by $40-50$ and $30-80 \%$, respectively, indicating the participation of p38MAPK and NF- $\mathrm{BB}$ signaling in the TNF- $\alpha$-induced MCP-1 and ICAM-1 expression. Furthermore, we evaluated the effects of glucosamine on the TNF- $\alpha$-induced phosphorylation of p38MAPK and NF-кB. As shown in Fig. 4, glucosamine dosedependently inhibited the phosphorylation of p38MAPK and $\mathrm{NF}-\mathrm{kB}(\mathrm{P}<0.05$ at 1 and $10 \mathrm{mM}$ glucosamine), but $\mathrm{N}$-acetyl-

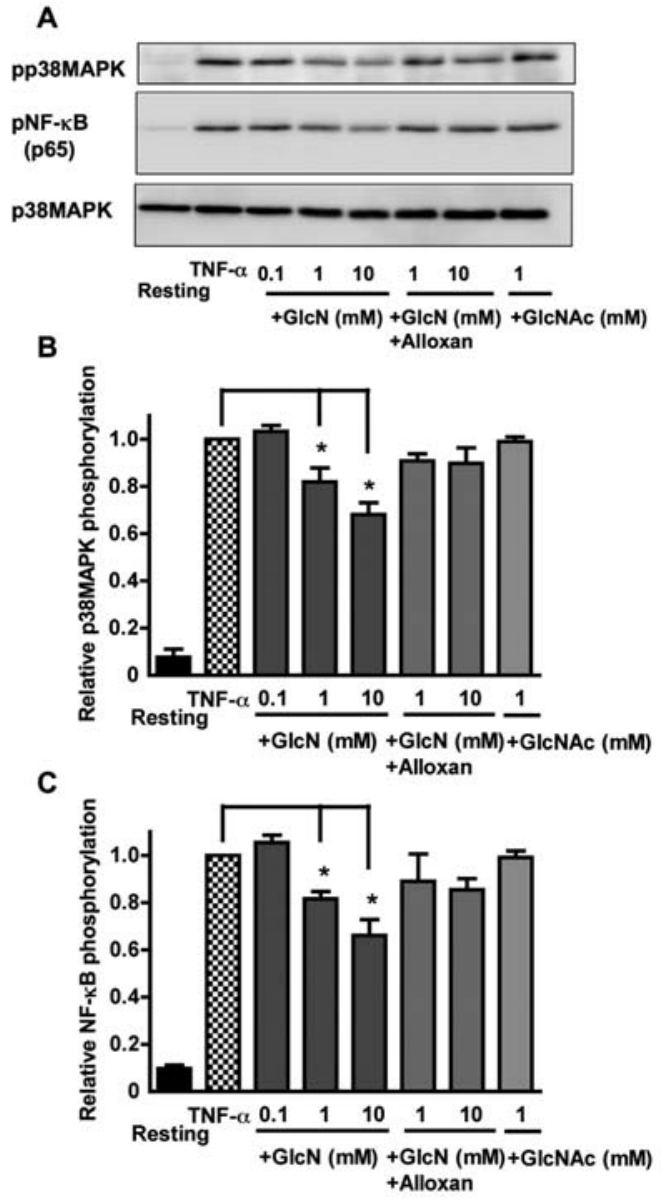

Figure 4. Effect of glucosamine on TNF- $\alpha$-induced p38MAPK and NF-кB phosphorylation. HUVECs were incubated without (Resting) or with $0.5 \mathrm{ng}$ / $\mathrm{ml} \mathrm{TNF}-\alpha$ in the absence or presence of 0.1-10 mM glucosamine (GlcN) or $1 \mathrm{mM}$ N-acetylglucosamine (GlcNAc). Alternatively, HUVECs were incubated with TNF- $\alpha$ in the presence of $1-10 \mathrm{mM}$ glucosamine and $0.5 \mathrm{mM}$ alloxan (Alloxan). Cell lysates were recovered, and phosphorylated p38MAPK (pp38MAPK) and NF-кB (pNF-кB) were evaluated by Western blotting (A). p38MAPK (a loading control) was also detected by Western blotting. The phosphorylation level was expressed as a ratio relative to TNF- $\alpha$ stimulation alone. Data are the mean \pm SEM from 3-4 independent experiments; ${ }^{*} \mathrm{P}<0.05$.

glucosamine did not, as observed for the effects on the MCP-1 and ICAM-1 expression (Figs. 1 and 2). These results suggest that glucosamine suppresses the expression of MCP-1 and ICAM-1 possibly by affecting p38MAPK and NF- $\kappa \mathrm{B}$ signaling.

Effect of glucosamine on O-GlcNAc modification. Modification of cellular proteins with $O$-linked-N-acetylglucosamine is involved in the modulation of cell functions, such as transcription and translation $(16,17)$. Thus, we investigated whether glucosamine induces $O$-GlcNAc modification, which accounts for the suppressive effect of glucosamine on endothelial cell activation. When the cells were incubated in the presence of $0.1-1 \mathrm{mM}$ glucosamine along with TNF- $\alpha$, $O$-GlcNAc modification was observed $(\mathrm{P}<0.05$ at $1 \mathrm{mM}$ glucosmaine), whereas TNF- $\alpha$ alone did not induce $O$-GlcNAc modification (Fig. 5). To note, alloxan $(0.5 \mathrm{mM})$, an inhibitor of $O$-GlcNAc modification, effectively prevented the glucosamine-induced $O$-GlcNAc modification $(\mathrm{P}<0.05)$ (Fig. 5). 
A
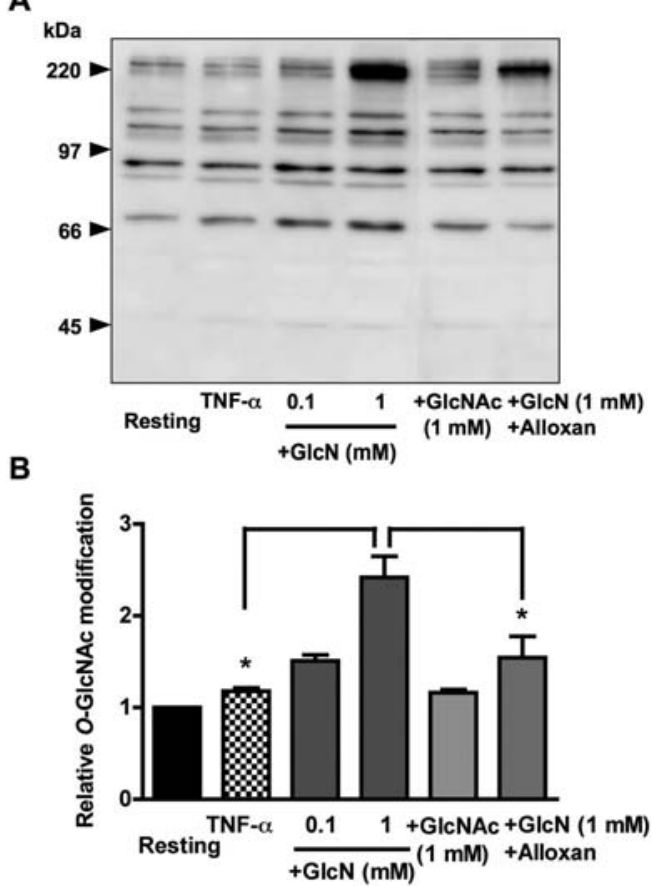

Figure 5. Glucosamine-induced $O$-GlcNAc modification in HUVECs. HUVECs were incubated without (Resting) or with $0.5 \mathrm{ng} / \mathrm{ml} \mathrm{TNF-} \alpha$ in the absence or presence of $0.1-1 \mathrm{mM}$ glucosamine $(\mathrm{GlcN})$ or $1 \mathrm{mM} \mathrm{N}$ acetylglucosamine (GlcNAc). Alternatively, HUVECs were incubated with TNF- $\alpha$ in the presence of $1 \mathrm{mM}$ glucosamine and $0.5 \mathrm{mM}$ alloxan (Alloxan). $O$-GlcNAc-modified proteins were evaluated by Western blotting (A). All the detected bands were quantified and totaled. $O$-GlcNAc modification levels were expressed as a ratio relative to the Resting cells (B). Data are the mean \pm SEM from 3 independent experiments; ${ }^{*} \mathrm{P}<0.05$.

As expected, $\mathrm{N}$-acetylglucosamine did not induce $O$-GlcNAc modification. We confirmed that $10 \mathrm{mM}$ glucosamine further induced $O$-GlcNAc modification, which was significantly suppressed by alloxan (data not shown).

Effect of alloxan on the glucosamine-induced suppression of $M C P-1$ and ICAM-1 protein expression. Glucosamine inhibited MCP-1 and ICAM-1 expression but N-acetylglucosamine did not. Similarly, glucosamine but not N-actylglucosamine induced $O$-GlcNAc modification. Since $O$ GlcNAc modification is involved in the modulation of cell functions $(16,17)$, we investigated the relationship between the glucosamine-induced protein $O$-GlcNAc modification and suppression of MCP-1 and ICAM-1 expression by using alloxan, which inhibited glucosamine-induced $O$-GlcNAc modification (Fig. 5). Of importance, alloxan abrogated the glucosamine-induced suppression of MCP-1 and ICAM-1 expression, although the effect was more profound against the suppression of ICAM-1 (Fig. 6). These findings suggest that glucosamine-induced $O$-GlcNAc modification is involved in the suppression of MCP-1 and ICAM-1 expression. Furthermore, we confirmed that alloxan abolished the glucosamine-induced suppression of p38MAPK and NF-кB phosphorylation (Fig. 4). Together, these observations suggest that glucosamine suppresses the TNF- $\alpha$-induced ICAM- 1 and MCP-1 expression possibly by affecting p38MAPK and $\mathrm{NF}-\kappa \mathrm{B}$ signaling via $O$-GlcNAc modification.
A
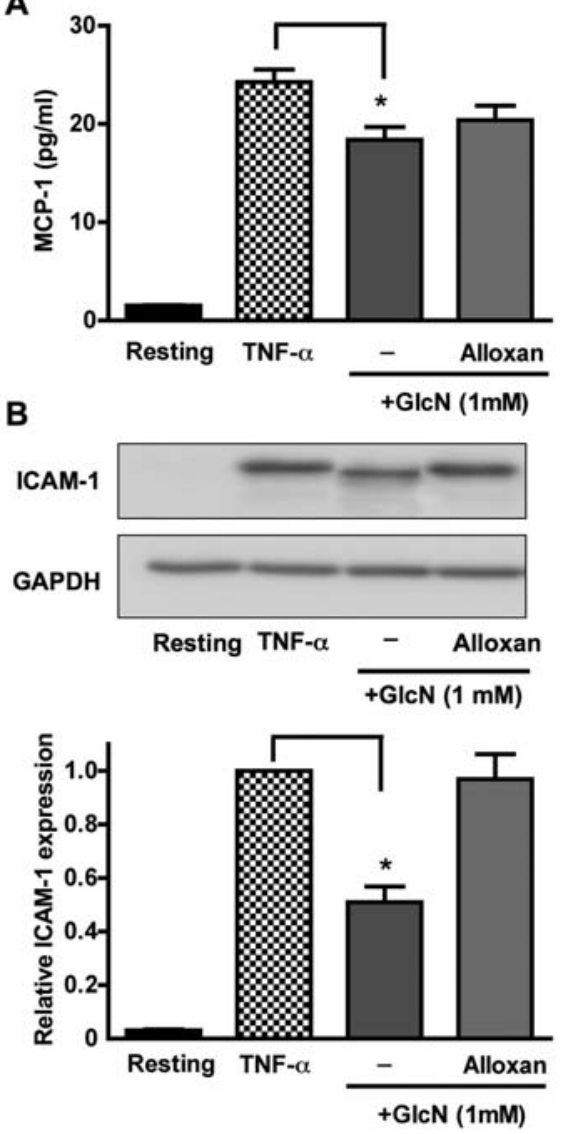

Figure 6. Effect of alloxan on glucosamine-induced suppression of MCP-1 and ICAM-1 expression. HUVECs were incubated without (Resting) or with $0.5 \mathrm{ng} / \mathrm{ml} \mathrm{TNF}-\alpha$ in the absence or presence of $1 \mathrm{mM}$ glucosamine $(\mathrm{GlcN})$. Alternatively, HUVECs were incubated with TNF- $\alpha$ in the presence of $1 \mathrm{mM}$ glucosamine and $0.5 \mathrm{mM}$ alloxan (Alloxan). Supernatants and cell lysates were recovered, and MCP-1 (A) and ICAM-1 (B) expression was quantitated by ELISA and Western blotting, respectively. GAPDH (a loading control) was also detected by Western blotting. ICAM-1 expression was expressed as a ratio relative to $\mathrm{TNF}-\alpha$ stimulation alone. Data are the mean \pm SEM from 6 independent experiments; ${ }^{*} \mathrm{P}<0.05$.

\section{Discussion}

Atherosclerosis is a chronic inflammatory disease which is characterized by infiltration of mononuclear leukocytes and lymphocytes into the intima through the expression of adhesion molecules on endothelial cells. Pro-inflammatory cytokines, such as tumor necrosis factor- $\alpha$ and interleukin-1ß (IL-1ß), are found in atherosclerotic lesions and contribute to the inflammatory process $(8,18)$. Previous studies have shown that these cytokines can induce the expression of cell adhesion molecules and chemokines and lead to the recruitment of leukocytes (19-21).

Here, we evaluated the effect of glucosamine on TNF- $\alpha$ induced expression of ICAM-1 and MCP-1, which play roles in the process of atherosclerotic plaque formation as an adhesion molecule and a chemoattractant protein, respectively. Upon activation, endothelial cells up-regulate adhesion molecules (such as ICAM-1), and monocytes can bind to endothelium through adhesion molecules. Subsequently, monocytes migrate into the arterial intima, and this process requires a chemoattractant (such as MCP-1) 
gradient. Once monocytes reside in the intima, they become intimal macrophages and internalize modified lipoproteins to become foam cells. Eventually, these macrophages congregate to the central core of atherosclerotic plaques (21).

Glucosamine is used to treat osteoarthritis $(9,10)$ and also exhibits anti-inflammatory actions. In brief, glucosamine suppresses neutrophil functions such as superoxide generation, granule enzyme release and chemotaxis (12), and inhibits platelet aggregation (22). In addition, glucosamine suppresses the activation (such as nitric oxide, $\mathrm{PGE}_{2}, \mathrm{IL}-8$ production) of synoviocytes (23). Furthermore, glucosamine inhibits ICAM-1 expression in human retinal pigment epithelial cells (13).

In this study, we investigated the effect of glucosamine on the activation of endothelial cells and revealed that glucosamine but not $\mathrm{N}$-acetylglucosamine inhibits the expression of ICAM-1 and MCP-1 at the mRNA and protein levels (Figs. 1 and 2). In separate experiments, we stimulated endothelial cells with another pro-inflammatory cytokine IL-1ß. We confirmed that IL-1B also induced the expression of MCP-1 and ICAM-1, and the expression was similarly suppressed by glucosamine as observed in the TNF- $\alpha$-induced MCP-1 and ICAM-1 expression (data not shown).

TNF- $\alpha$ activates a variety of signaling cascades (such as p38MAPK and NF-кB pathways) that leads to the induction of inflammatory response (15). We demonstrated using p38MAPK and IKK inhibitors that TNF- $\alpha$ induces the expression of ICAM-1 and MCP-1 via p38MAPK and NF- $\mathrm{BB}$ signaling (Fig. 3). Furthermore, we revealed that glucosamine suppressed, not only the expression of MCP-1 and ICAM-1 (Figs. 1 and 2), but also the phosphorylation of p38MAPK and NF-кB (Fig. 4). These observations suggest that glucosamine inhibits endothelial cell activation (i.e., MCP-1 and ICAM-1 expression) possibly via the suppression of intracellular signaling including p38MAPK and NF-кB.

It is now recognized that the addition of $O$-linked $\mathrm{N}$-acetylglucosamine $(O-\mathrm{GlcNAc})$ to target proteins may modulate cellular functions, such as nuclear transport, transcription, translation, cell signaling, apoptosis and cell shape $(16,17)$. In this context, it has been recently found that glucosamine treatment protects rat hearts from ischemia-reperfusion injury, accompanied by the increased $O$-GlcNAc levels and attenuated phosphorylation of p38MAPK (24). To note, Western blotting using anti-O-GlcNAc monoclonal antibody revealed that glucosamine but not $\mathrm{N}$-acetylglucosamine induced the $O$-GlcNAc-modification in endothelial cells (Fig. 5), which was negatively correlated with endothelial cell activation (the phosphorylation of $\mathrm{p} 38$ MAPK and NF- $\mathrm{KB}$, and the expression of MCP-1 and ICAM-1) (Figs. 1, 2 and 4). Mammalian cells contain $O$-GlcNAc transferase (OGT), an $O$-GlcNAc-modifying enzyme and $O$-N-acetylglucosaminidase $(O$-GlcNAcase), an $O$-GlcNAc-modification degrading enzyme $(16,17)$. Thus, we further investigated the effect of alloxan, an OGT inhibitor. Alloxan abrogated not only the glucosamine-induced $O$-GlcNAc-modification but also the glucosamine-induced suppression of MCP-1 and ICAM-1 expression, and p38MAPK and NF- $\mathrm{B}$ phosphorylation (Figs. 4, 5 and 6). Together these observations suggest that glucosamine modulates endothelial cell activation possibly via $O$-GlcNAc modification, which likely affects intracellular signaling, such as p38MAPK and $\mathrm{NF}-\mathrm{\kappa B}$, and expression of target proteins, such as MCP-1 and ICAM-1.

In conclusion, glucosamine is likely to suppress TNF- $\alpha-$ induced ICAM-1 and MCP-1 expression in endothelial cells, possibly by affecting $\mathrm{p} 38 \mathrm{MAPK}$ and NF- $\mathrm{KB}$ signal pathways via $O$-GlcNAc modification. Thus, we speculate that glucosamine affects endothelial cell activation, thereby exhibiting anti-inflammatory action on atherosclerosis. In this context, it is important to note that administration of glucosamine significantly reduced atherosclerotic lesions in the aortic roots of apoE-deficient mice (25). The in vivo effect of glucosamine on atherosclerotic disorders should be carefully evaluated in the future.

\section{Acknowledgements}

We thank Drs Yuko Tsutsumi-Ishii and Shin Yomogida for the helpful discussion during the research. This work was supported in part by a grant from the Atopy (Allergy) Research Center, Juntendo University and a Grant-in-Aid for $21 \mathrm{st}$ Century COE Research from the Ministry of Education, Culture, Sports, Science and Technology, Japan.

\section{References}

1. Bailleul S, Couderc R, Rossignol C, Fermanian J, Boutouchent F, Farnier MA and Etienne J: Lipoprotein(a) in childhood: relation with other atherosclerosis risk factors and family history of atherosclerosis. Clin Chem 41: 241-245, 1995.

2. Hansson GK: Inflammation, atherosclerosis, and coronary artery disease. N Engl J Med 352: 1685-1695, 2005.

3. Bolick DT, Orr AW, Whetzel A, Srinivasan S, Hatley ME, Schwartz MA and Hedrick CC: 12/15-Lipoxygenase regulates intercellular adhesion molecule-1 expression and monocyte adhesion to endothelium through activation of RhoA and nuclear factor-кB. Arterioscler Thromb Vasc Biol 25: 2301-2307, 2005.

4. Blanco-Colio LM, Muñoz-García B, Martín-Ventura JL, Alvarez-Sala LA, Castilla M, Bustamante A, LamuelaRaventós RM, Gómez-Gerique J, Fernández-Cruz A, Millán J and Egido J: Ethanol beverages containing polyphenols decrease nuclear factor kappa-B activation in mononuclear cells and circulating MCP-1 concentrations in healthy volunteers during a fat-enriched diet. Atherosclerosis 192: 335-341, 2007.

5. Liu SX, Hou FF, Guo ZJ, Nagai R, Zhang WR, Liu ZQ, Zhou ZM, Zhou M, Xie D, Wang GB and Zhang X: Advanced oxidation protein products accelerate atherosclerosis through promoting oxidative stress and inflammation. Arterioscler Thromb Vasc Biol 26: 1156-1162, 2006.

6. Braunersreuther V and Mach F: Leukocyte recruitment in atherosclerosis: potential targets for therapeutic approaches? Cell Mol Life Sci 63: 2079-2088, 2006.

7. Tipping PG and Hancock WW: Production of tumor necrosis factor and interleukin-1 by macrophages from human atheromatous plaques. Am J Pathol 142: 1721-1728, 1993.

8. Tedgui A and Mallat Z: Cytokines in atherosclerosis: Pathogenic and regulatory pathways. Physiol Rev 86: 515-581, 2006.

9. Crolle G and D'Este E: Glucosamine sulphate for the management of arthrosis: a controlled clinical investigation. Curr Med Res Opin 7: 104-109, 1980.

10. Reginster JY, Deroisy R, Rovati LC, Lee RL, Lejeune E, Bruyere O, Giacovelli G, Henrotin Y, Dacre JE and Gossett C: Long-term effects of glucosamine sulphate on osteoarthritis progression: a randomised, placebo-controlled clinical trial. Lancet 357: 251-256, 2001.

11. Meininger CJ, Kelly KA, Li H, Haynes TE and Wu G: Glucosamine inhibits inducible nitric oxide synthesis. Biochem Biophys Res Commun 279: 234-239, 2000.

12. Hua J, Sakamoto K and Nagaoka I: Inhibitory actions of glucosamine, a therapeutic agent for osteoarthritis, on the functions of neutrophils. J Leukoc Biol 71: 632-640, 2002. 
13. Chen JT, Liang JB, Chou CL, Chien MW, Shyu RC, Chou PI and Lu DW: Glucosamine sulfate inhibits TNF-alpha and IFNgamma-induced production of ICAM-1 in human retinal pigment epithelial cells in vitro. Invest Ophthalmol Vis Sci 47: 664-672, 2006.

14. Ju Y, Hua J, Sakamoto K, Ogawa H and Nagaoka I: Glucosamine, a naturally occurring amino monosaccharide modulates LL-37-induced endothelial cell activation. Int J Mol Med 22: 657-662, 2008.

15. Bradley J: TNF-mediated inflammatory disease. J Pathol 214: 149-160, 2008.

16. Wells L, Vosseller K and Hart GW: Glycosylation of nucleocytoplasmic proteins: signal transduction and O-GlcNAc. Science 291: 2376-2378, 2001.

17. Hanover JA: Glycan-dependent signaling: O-linked Nacetylglucosamine. FASEB J 15: 1865-1876, 2001.

18. Kirii H, Niwa T, Yamada Y, Wada H, Saito K, Iwakura Y, Asano M, Moriwaki H and Seishima M: Lack of interleukin-1ß decreases the severity of atherosclerosis in ApoE-deficient mice. Arterioscler Thromb Vasc Biol 23: 656-660, 2003.

19. Gu L, Okada Y, Clinton SK, Gerard C, Sukhova GK, Libby P and Rollins BJ: Absence of monocyte chemoattractant protein-1 reduces atherosclerosis in low density lipoprotein receptordeficient mice. Mol Cell 2: 275-281, 1998.
20. Boyle JJ: Macrophage activation in atherosclerosis: pathogenesis and pharmacology of plaque rupture. Curr Vasc Pharmacol 3: 63-68, 2005.

21. Galkina E and Ley K: Vascular adhesion molecules in atherosclerosis. Arterioscler Thromb Vasc Biol 27: 2292-2301, 2007.

22. Hua J, Suguro S, Iwabuchi K, Tsutsumi-Ishii Y, Sakamoto K and Nagaoka I: Glucosamine, a naturally occurring amino monosaccharide, suppresses the ADP-mediated platelet activation in humans. Inflamm Res 53: 680-688, 2004.

23. Hua J, Sakamoto K, Kikukawa T, Abe C, Kurosawa H and Nagaoka I: Evaluation of the suppressive actions of glucosamine on the interleukin-1ß-mediated activation of synoviocytes. Inflamm Res 56: 432-438, 2007.

24. Fülöp N, Zhang Z, Marchase RB and Chatham JC: Glucosamine cardioprotection in perfused rat heart associated with increased $\mathrm{O}$-Linked $\mathrm{N}$-acetylglucosamine protein modification and altered p38 activation. Am J Physiol Heart Circ Physiol 292: H2227-H2236, 2007.

25. Duan W, Paka L and Pillarisetti S: Distinct effects of glucosamine on vascular endothelial and smooth muscle cells: evidence for a protective role for glucosamine in atherosclerosis. Cardiovasc Diabetol 4: 16, 2005. 